\title{
AC 2008-1016: ENGINEERING INSTRUCTION IN NONDESTRUCTIVE TESTING OF MATERIALS (NDT) USING THE CAPILLARY DIFFUSION METHOD.
}

\section{Guido Lopez, Old Dominion University}

Dr Lopez is a faculty member of Old Dominion University, Norfolk, VA. He is an alumnus of Northeastern University, Boston, MA. He has served in academic and administrative positions such as engineering faculty at Northeastern University, Wentworth Institute of Technology in Boston, MA, and Chair of the Engineering Math and Science Division at Daniel Webster College, Nashua, NH. He has performed applied research at the NASA John Glenn Research Center in the field of solar power generation for the international space station alpha. He is a technical consultant in areas of power generation, and non destructive testing and evaluation of materials.

\section{Ilya Leipunsky, Russian Academy of Science}

Dr. Leipunsky is a Leading Senior staff scientist at the Institute of Energy Problems of Chemical Physics of the Russian academy of Science, Moscow, Russia. He was a scientist member of the Russian Space Program for 14 years $(1976$ - 1990). His current research focuses on surface chemistry, nanotechnology, and NDT and NDE.

\section{Nadezda Berezkina, Russian Academy of Sciences}

Dr. Nadezda Berezkina is a Senior staff scientist at the Institute of Energy Problems of Chemical Physics of the Russian Academy of Sciences (INEP CP RAS), Moscow Russia. She participated as staff scientist in the Russian Space Program during the development of the Russian Space Orbiter "Buran" between 1985 and 1990. She is inventor of specialized indicator materials for penetrant inspection methods of surface defects. She currently performs theoretical and applied research in areas of material science and nondestructive testing and evaluation of materials and energy equipment. 


\title{
ENGINEERING INSTRUCTION IN NONDESTRUCTIVE TESTING OF MATERIALS (NDT) USING THE CAPILLARY DIFFUSION METHOD
}

\begin{abstract}
In a great majority of educational cases, "testing of materials" in the laboratory implies "destructive" techniques consisting of using universal testing machines (UTMs), where materials are brought to a "failure condition" under tension, compression, shear, bending or torsion. Common objectives associated with these types of tests are: the evaluation of materials moduli of elasticity and rigidity, yield strength, strain, ultimate strength, etc. In engineering practice, however, "in-situ" nondestructive testing (NDT) of materials are highly preferable, in order to evaluate rapidly the condition, failure potential, usefulness and serviceability of engineering materials. Thus, nondestructive testing of materials ought to be an essential ingredient of engineering education and training, since it plays a significant role in design, manufacturing and evaluation of engineering equipment. This paper presents an inexpensive, simple and effective method to convey to engineering students the underlying principles of NDT, based on an innovative technique referred to as Capillary Diffusion Method (CDM), which is classified within the category of non-destructive Penetrant Testing (PT). CDM is relatively unknown in the United States, but, it has been used for several years in the former Soviet Union, and more recently, in the Russian Federation. CDM proves to be quite versatile and considerably faster than conventional PT techniques used in the U.S. In this paper, the underlying science behind the CDM technique is discussed in detail, as well as, the academic benefits and educational potential derived from the inclusion of CDM in engineering academic curriculum. Mathematical, graphical and numerical documentation are presented in order to substantiate the suitability of $\mathrm{CDM}$ as an educational tool to teach Nondestructive Testing in engineering programs such as: Mechanical engineering, Chemical engineering, Civil engineering, Aeronautical, Aerospace engineering, Power Plant Engineering, and Nuclear engineering.
\end{abstract}

\section{Introduction}

Nondestructive testing and evaluation of materials is an ancient practice. Early metalworkers, for example, report the use of "visual" or "sonic" techniques to determine the quality and usefulness of their products. Today, Nondestructive Testing (NDT) and Nondestructive Evaluation (NDE) are methods of considerable importance to inspect and determine the integrity of engineering materials, equipment and systems. Several engineering techniques have been and continue to be developed for accurate NDT and NDE of materials. Examples of these techniques in engineering applications include: X-rays, Thermography, Ultrasound, Eddy Current, Magnetic Particle, and Penetrant Testing ${ }^{6,8,12}$.

Materials Testing is quite likely to be part of engineering lab curricula and training, particularly, in fields such as, Civil, Structural, Mechanical, Power Plant, Nuclear, Aeronautical and Aerospace. Often, however, testing of engineering materials in the laboratory involves "destructive" procedures where standard specimens are brought to the "failure condition" or to the "breaking point". Familiar destructive tests include tensile, compressive, shear, torsion and fatigue. The most common educational objective from these types of tests is the quantification 
of mechanical properties, such as, the moduli of elasticity and rigidity, yield strength, strain, ultimate strength, toughness, resilience, etc.

Incorporating "Non destructive" Testing and Evaluation of materials in engineering training broaden students perspective of material testing and bring considerable educational benefit in this area. There are several technologies available for Non Destructive testing. Some of these technologies are quite sophisticated and expensive. Among them, however, Penetrant Testing (PT) is distinguished by its simplicity, flexibility, and affordability ${ }^{13,20}$.

Penetrant Testing is a technique capable of detecting surface discontinuities and material flaws (cracks, microporosity, blisters, etc.) using substances that seep into surface defects analogous to the way coffee deposits detect a crack of a ceramic cup (Figure 1). In a majority of cases, the penetrant used is commonly in the liquid phase. For this reason, this NDT technique is often known as "Liquid Penetrant Test" (LPT).

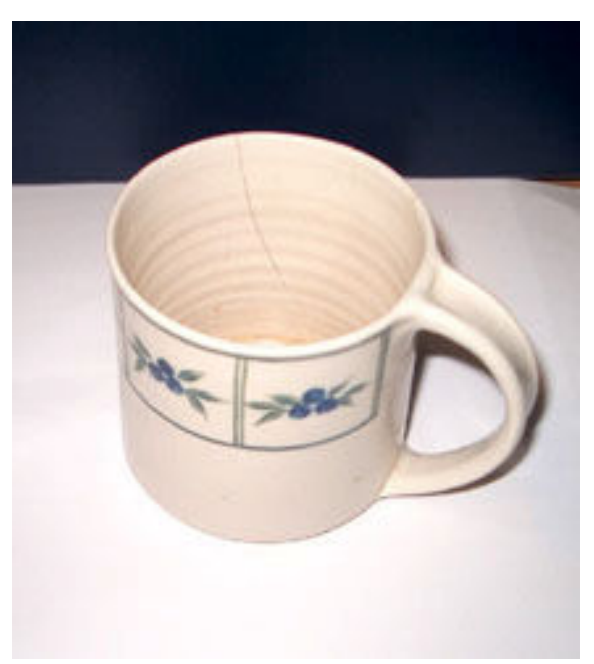

Figure 1. Coffee seepage into cracked wall of ceramic cup. In this case, a simple visualization of the crack is possible due to the concentration of coffee particles at the opening of the crack.

In general, Penetrant Testing (PT) involves the following steps: (1) pre-cleaning and surface preparation of the part under test, (2) selection and application of visible or fluorescent dyes that are capable to penetrate discontinuities by capillary action, (3) penetrant dwelling, i.e.: allowing the penetrant to stay in contact with the surface for a suitable period of time, (4) removal of excess penetrant using special solvents and/or emulsifiers, (5) extraction of penetrant by special developers and, subsequent inspection of discontinuities, and (6) post-cleaning of the part(s) tested in order to remove developer and residual penetrant.

Pre-cleaning, post-cleaning and lengthy dwelling times are counted as primary disadvantages of conventional PT technologies used in the U.S. In fact, careful pre-cleaning is essential to decontaminate the inspected parts, and secure the reliability of the techniques. The presence of contaminants can easily mask defects resulting in inaccurate inspection of defects. The choice of 
the proper dwell time is also a critical phase of the PT technique. Typical dwell times may range from 5 minutes to 60 minutes. If the dwell time is too long, conventional penetrants may dry and the test may be ruined. Suitable dwell times for a specific application can only be determined empirically and depend highly on the type of application and penetrant formulation.

Finally, if after the test, the part inspected is determined to be acceptable, it needs to be cleaned thoroughly, in order to ensure its continuing serviceability. These drawbacks of conventional US-based PT methods are easily overcome and/or substantially reduced in the Russian-based CDM PT technique explained below.

PT has been used for several years for determining the integrity of machinery parts and components. In the late $19^{\text {th }}$ Century, for example, inspectors of locomotives are reported using oil diluted with kerosene as the penetrant material ${ }^{15,16}$. Since then, penetrant formulations have evolved substantially. Nevertheless, all penetrants commercially available in the US for NDT and NDE are dye formulations that can be catalogued within two basic types: Visual Penetrants, and Fluorescent Penetrants. Fluorescent dies require the help of ultraviolet light to detect defects, while visual penetrants do not.

Penetrant Testing is extensively used for NDT and NDE of materials utilized in the power generation, aeronautical and aerospace industries. Because its wide use, PT standards and testing specifications have been established in the U.S. by professional organizations and by the military (Examples: MIL-STD-6866, ASTM E 1417) in order to ensure tests reliability and accuracy. Performance checks, for example, are required in reference to the "Star Burst" penetrant testing and monitoring panel (TAM). These are specialized panels that are utilized to determine sensitivity levels, tolerances and/or degradation of the technique.

\section{The Capillary Diffusion Method (CDM)}

The Capillary Diffusion Method CDM is a penetrant testing technique researched and developed in the former Soviet Union, and relatively unknown in the United States ${ }^{3,4,10}$. Although the principle behind CDM is similar to the conventional PT techniques used in the U.S., the penetrant formulation used in CDM simplifies and shortens the test time considerably. In CDM, there is no need for specialized emulsifiers and developers. This lowers the costs associated with NDT and NDE, substantially. It also makes CDM an ideal technique for implementing simple, inexpensive, but effective educational experiments, in order convey the basic principles of NDT and NDE in engineering instruction.

Step-by-step procedures to apply the CDM technique in NDT experiments are explained in reference 3.

In general, $\mathrm{CDM}$ utilizes a liquid mixture of three materials as the penetrant: a volatile component (CDM-1) that reacts with the indicator material, a volatile component (CMD-2) that accelerates the evaporation of the penetrant and improves its wetting capability, and water.

The solution concentration of species depends on the material and character of the part being tested. This type of penetrant spreads easily over the surface of the material and provides 
complete and even coverage while being drawn into defects by capillary action. At this point, unlike conventional PT methods, the excess penetrant evaporates and there is no need of solvents or emulsifiers. The remaining CDM penetrant inside the defects continues to evaporate. This vapor is then utilized by the CDM technique to provide a highly visible registration of defects with the help of a specialized and easily replaceable indicator material.

All these are important characteristics sought by manufacturers of conventional penetrants in the U.S. In spite of its simplicity and low cost, the CDM penetrant meets characteristics that allow it to surpass the performance and sensitivity of conventional penetrants produced in the U.S.

An additional advantage of the CDM technique is that it provides visible imprints of cracks porosity or other surface discontinuities on the indicator material (see figure 5), unlike conventional PT techniques where the inspection is performed visually on the specimen. Furthermore, the detection and recording of defects is considerably faster than conventional PT.

CDM is indeed a versatile technique that can be used in a wide variety of engineering materials including metals, plastics, ceramics and composite materials without additional requirements. In fact, CDM has been, and continues to be, tested in the field in several areas of industrial inspection that includes power generation systems, petrochemical plants, aerospace and aeronautics.

\section{Physical bases of CDM}

CDM has its roots in the phenomenon of capillary action, i.e.: a phenomenon by which a liquid "wets" a solid surface due to the adhesive forces at the liquid-solid interface. In liquid penetrant testing, good "wetting" characteristics of the liquid penetrant favors its flow into surface cavities and cracks facilitating in this way the detection of defects. Wetting ability is measured in terms of the "contact angle" $\theta$ between the liquid surface and the solid surface (See figure 2).

Good wetting characteristic of a liquid implies small contact angle, and a better capability to be drawn and fill surface voids ${ }^{2,5,9,14,18}$. Wetting ability is also associated to the "surface tension" of the liquid, i.e.: the energy of surface formation at the existing interfaces (liquid-gas, solid-liquid, solid-gas).

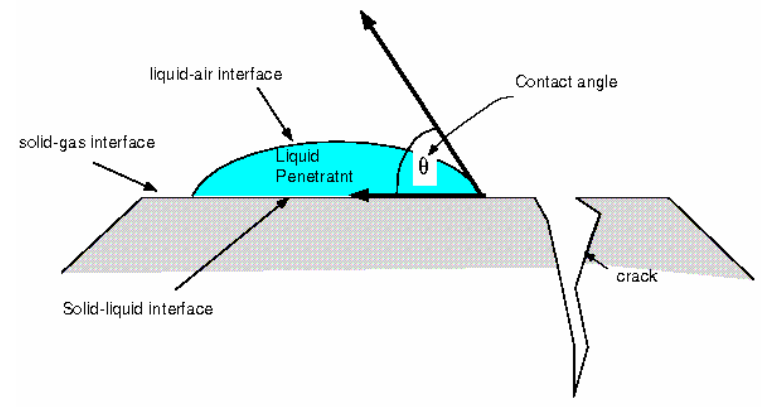

Figure 2. Contact angle between a liquid penetrant a solid surface. 
In CDM the driving pressure, also referred to as "capillary pressure" forces the liquid penetrant to fill the voids at the surface. This pressure is directly proportional to the contact angle and the surface tension, and inversely proportional to the crack opening and depth infiltrated by the liquid. The penetrant will continue to fill voids until the driving pressure is counteracted by an opposing pressure resulting mainly from the trapped air in the void. At this time, the maximum penetration depth is reached. Subsequently, a brief "stand time" interval is required to allow the excess penetrant on the surface to evaporate. The minimum "stand time" depends on the surface roughness. Next, the diffusion flux of vapor originating from the flaws is used to furnish information about the defect. In the CDM, this is performed by using an indicator material that is attached to the surface for a few seconds (exposure time).

The CDM indicator consists of a special sheet chemically treated to react with the molecules diffusing out from the flaw in gaseous form, and designed to provide a colored imprint of the surface defects. Figure 3 depicts this process. The indicator utilized in the CDM technique is totally safe, and readily available in the U.S. for a modest price ${ }^{11}$.
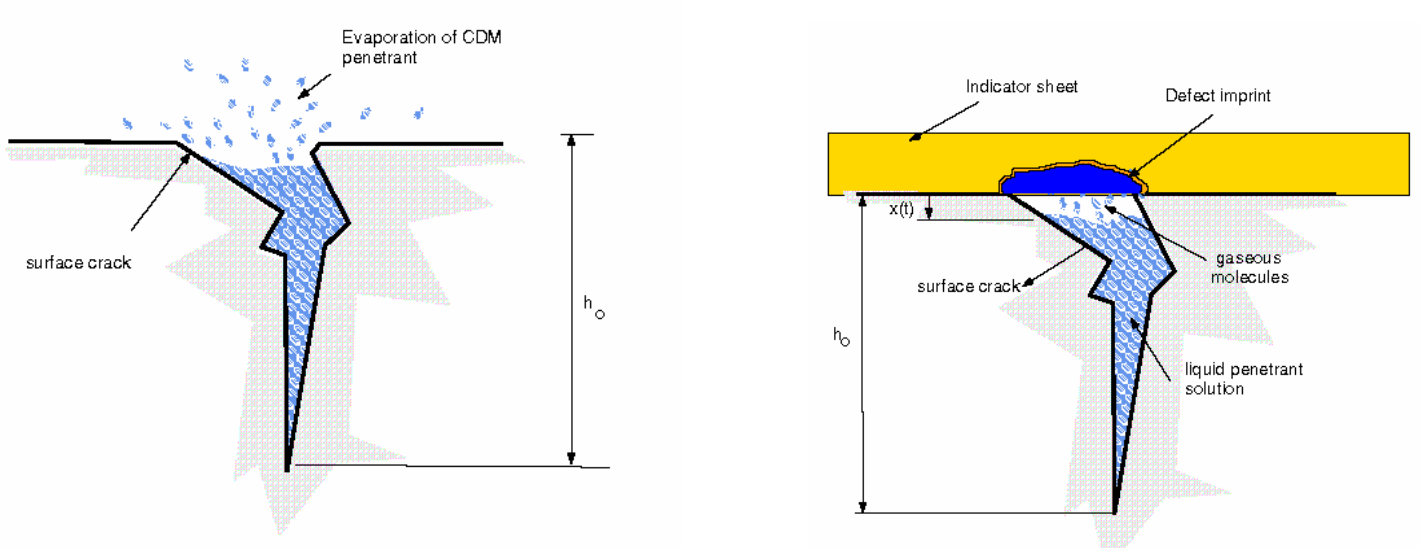

Figure 3. CDM defect detection process.

The key characteristic of the CDM test is the diffusion flux rate of the evaporating penetrant out of the flaw, and into the indicator. The solution concentration of the penetrant is volatile by design, and its purpose is twofold, (a) to furnish information about the presence and depth of defects by reacting with the indicator, and (b) to vanish from the flaws and make the postcleaning unnecessary.

Examples of experimental results obtained though CDM are presented in Figures 4 and 5. Figure 4 shows a test on the blade of a turbine. A clear defect is revealed by CDM at one of the edges of the blade. Such detection is not possible by a simple visual inspection of the blade. Figure 5 shows a test performed on a block of the thermal protection system (TPS) designed for the Russian space shuttle BURAN. This is a highly specialized application of the CDM technology aiming at resolving issues related to safety of spacecraft at its re-entry from space. 

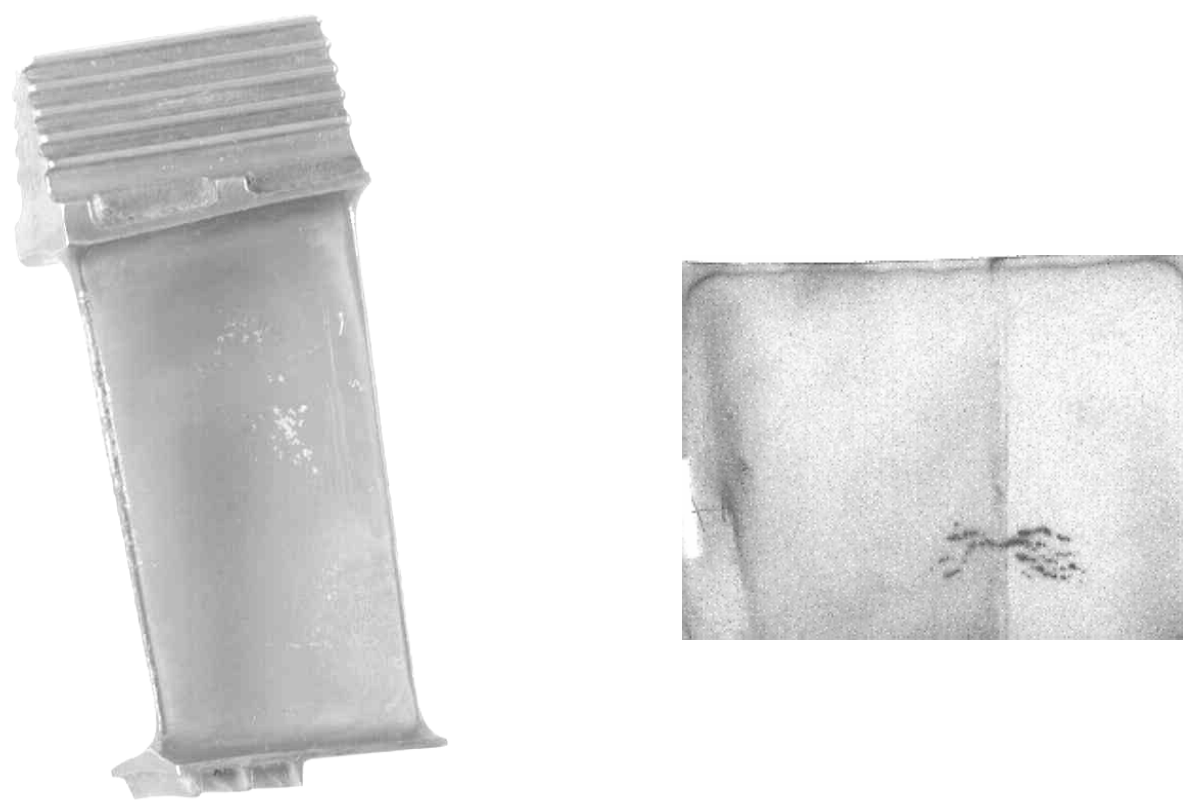

Figure 4. CDM technology revealing a crack defect at the right edge of a turbine blade

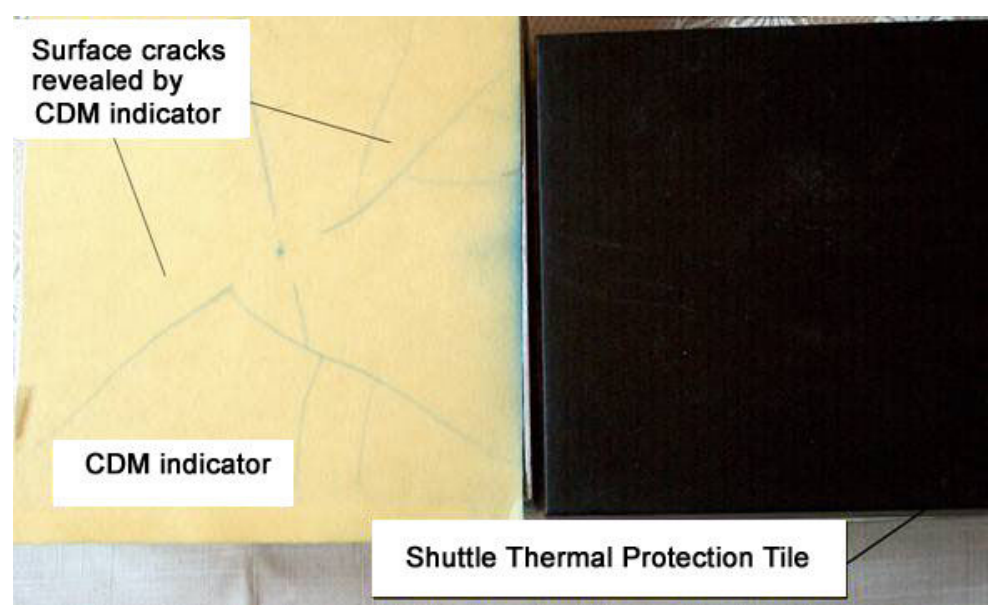

Figure 5. CDM indicator revealing flaws of the Thermal Protection System designed for the Russian space shuttle BURAN.

\section{Underlying theory of CDM detection of surface defects.}

A theoretical estimation of the maximum depth of flaw penetration by the CDM penetrant is performed at the mechanical equilibrium condition achieved when the capillary pressure, atmospheric pressure, internal hydrostatic pressure and pressure of entrapped air balance each other out. 
Under this condition, the depth of penetration $h$, of a liquid into a wedge void cavity by capillary action is estimated from the equation:

Where:

$$
h=h_{o}+\sigma \cos \theta \frac{h_{o}}{P_{a} d}-\left[(\sigma \cos \theta)^{2}\left(\frac{h_{o}}{P_{a} d}\right)^{2}+h_{o}^{2}\right]^{\frac{1}{2}}
$$

$\sigma=$ Surface tension of liquid

$P_{a}=$ Atmospheric pressure

$\theta=$ Contact angle

$h_{o}=$ Actual depth of cavity

Figure 6 shows a normalized plot of the estimated depth of penetration for two common liquids, as a function of the opening width $d$ of the wedge void cavity. It must be noticed that the theoretical depth of penetration presented above, underestimates the actual depth of penetration of the CDM penetrant in surface defects. Because air is soluble in the CDM penetrant, entrapped air in voids can easily be displaced by it, therefore, achieving higher values of penetration depth, and providing a better indication of the depth of the defect.

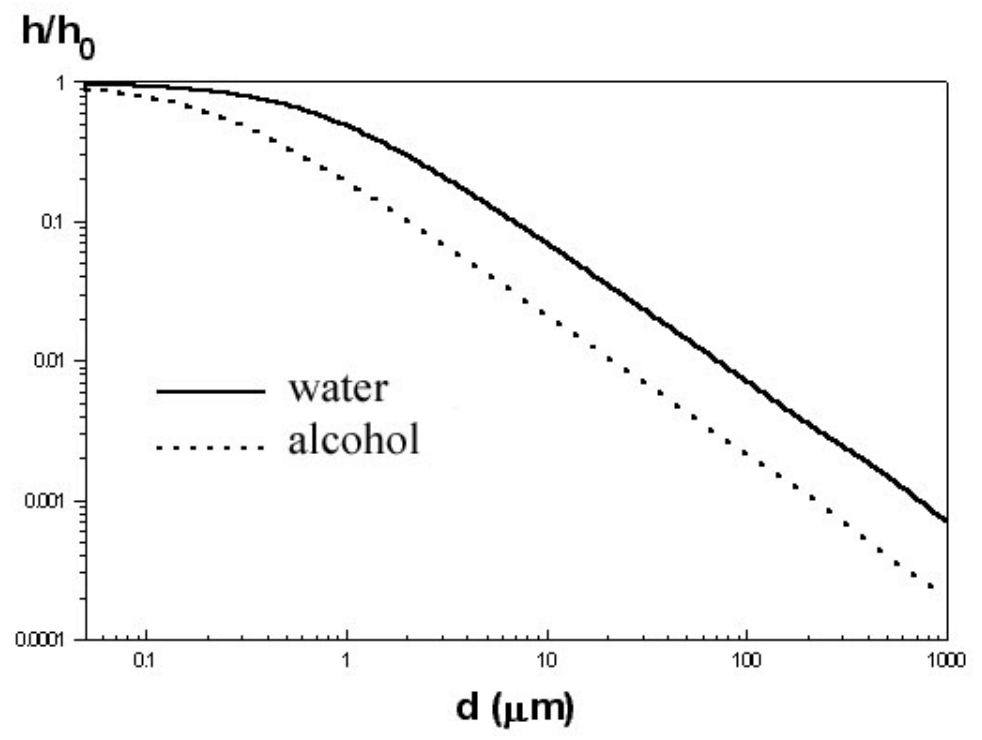

Figure 6. Theoretical penetration depth by capillary action as a function of wedge void opening

An estimation of the time of penetration of liquids into voids by capillary action $(t)$ can be performed using the following equation:

$$
t=\frac{3 \mu h^{2}}{\sigma d \cos \theta}
$$


Where,

$h=$ depth of penetration

$\mu=$ coefficient of dynamic viscosity

$\sigma=$ Surface tension of liquid

$\theta=$ Contact angle

In the case of CDM penetrant, the time of penetration is minimal (a few seconds), as compared to several minutes even hours in conventional dye penetrants. Among other reasons, this is due to the low viscosity of the CDM penetrant solution.

Upon maximum penetration depth, and evaporation of excess at the surface, the remaining CDM penetrant in the void will start evaporating. From this moment on, the diffusion rate of CDM penetrant vaporizing out of the defect is observed to change with respect to time. The CDM technology utilizes this variation to provide an indication of the depth of defects.

Theoretically, the diffusion flux of the constituents of CDM penetrant in the solution can be estimated by solving the standard diffusion equation,

Where,

$$
\frac{\partial n_{i}}{\partial t}=D_{i} \frac{\partial^{2} n_{i}}{\partial x^{2}}
$$

$n_{i}=$ concentration of species $i$ of CDM penetrant solution.

$D_{i}=$ Diffusion coefficient of species $i$ in CDM penetrant.

$x=$ coordinate of the air-CDM penetrant interface relative to the defect opening.

$t=$ stand time $(\mathrm{s})$.

Similarly, the concentration gradient of the constituents of the CDM penetrant in the solution at the interface air-CDM penetrant can be modeled by,

$$
D_{i} \frac{\partial n_{i}}{\partial x}=D_{i a} \cdot f\left(N_{i}, x\right)
$$

Where,

$D_{i \mathrm{a}}=$ Diffusion coefficient of solution species $i$ in air

$f\left(N_{i}, x\right)=$ function of species concentration $i$ in air above the air-CDM penetrant interface $\left(N_{i}\right)$, and the coordinate $\mathrm{x}$.

The simultaneous solution of the previous system of equations allows one to predict the diffusion flux of the volatile component (CDM-1) that reacts with the indicator material. Subsequently, one can infer the presence and size of defects on surfaces of materials by examining the characteristics of the mathematical prediction.

Figure 7 presents the normalized diffusion flux $I / I_{o}$ of CDM- 1 as a function of the stand time (t), for a concentration value $\gamma=25 \%$ of $\mathrm{CDM}-2$, ambient temperature $25{ }^{\circ} \mathrm{C}$, and relative humidity $60 \%$. In this case, $I_{o}$ is the initial diffusion flux. 


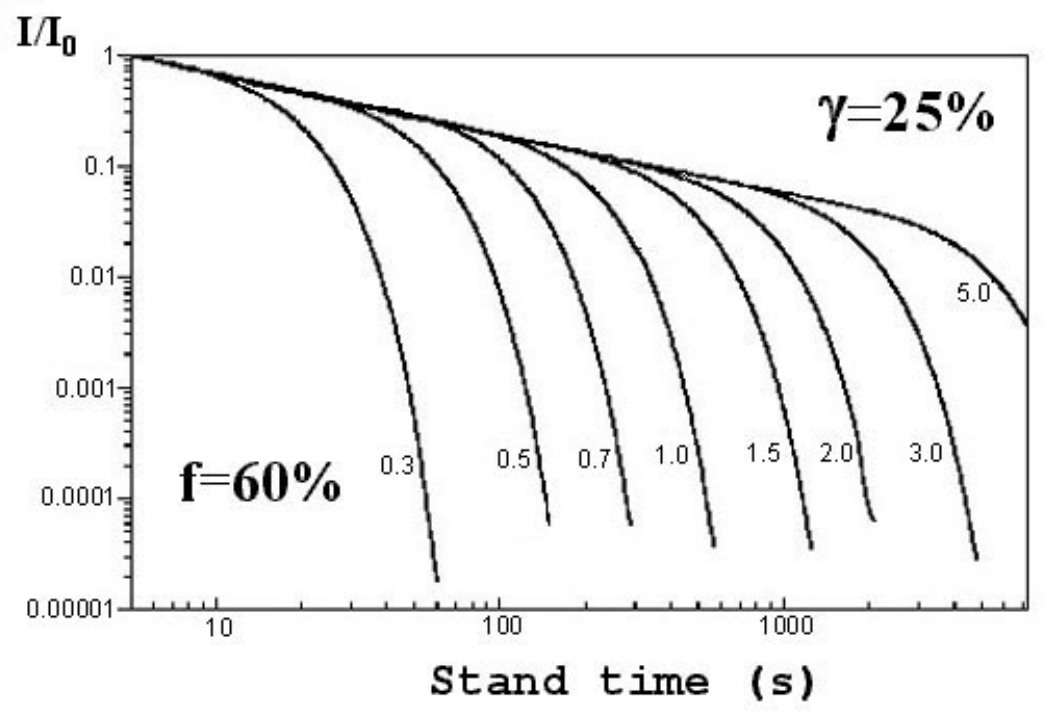

Figure 7. Theoretical diffusion flux of volatile component CDM-1 with respect to time for defect depths ranging between $0.3 \mathrm{~mm}$ and $5 \mathrm{~mm}$.

It is clear from this response, that the diffusion flux is dependent on the depth of the void. Two clear stages of behavior are distinguished from the figure. The first stage is fairly linear for any depth of defect and its duration can be used to determine the presence and depth of a flaw. During this stage, imprints of defects can be obtained since the level of CDM-1 flux allows this to react with the indicator material. Therefore, observation of imprints captured by the CDM indicator at short intervals within this stage will provide the information about the depth of the flaw. The second stage is characterized by a rapid decrease in diffusion flux rate, and therefore, no imprints of defects can be obtained on the indicator material during this stage.

\section{CDM, an Educational Tool to Convey Engineering Principles of Safety and Reliability.}

Engineering is a creative profession that aims at resolving technical problems and satisfying human needs. Among the most important aspects of these objectives are reliability and safety. In many cases the reliability and safety of engineering equipment are of primordial importance to guarantee the well being of living creatures.

Consider, for instance, aero transportation. There is a myriad of elements and parts in an aircraft that during design and maintenance require exhaustive checks and rechecks to ensure the proper functioning during flight. Cracks or porosity on the turbine blades of an aircraft engine flying at $30,000 \mathrm{ft}$, for example, could certainly bring disastrous consequences. Therefore, proper testing of the blades during the design process, as well as, under simulated conditions of operation and schedule maintenance will provide engineers with the necessary information about their reliability and safety.

There are innumerable examples where the notions of safety and reliability are of great significance to achieve objectives in human endeavors that use mechanical equipment. Failure to 
give proper attention to these aspects has resulted in tragedy. Refer, for instance, to the recent Orbiter Columbia disaster. Fortunately, engineering has learned and continue to learn from failure tenaciously. Exhaustive and meticulous tests were conducted on the debris recovered from the Space Shuttle in order to determine the causes of the accident and learn from mistakes made. Nondestructive testing was part of this study.

Non destructive testing is quite desirable in inspection of parts. Given the fact that mechanical engineering deals in great part with technology where reliability and safety are an important component of designed hardware, learning about techniques for nondestructive testing can substantially enhance the training of engineering students, and help to convey the principles and practice of safety and reliability.

As noted above, quite frequently, principles of safety and reliability are conveyed through impressionable "destructive" test techniques in engineering training. Although these techniques have matured substantially over the years, the most common limitation lies on the standard geometries of specimens utilized to observe and study failure. In fact, the actual geometries of parts and components designed and manufactured for engineering equipment may substantially differ from the standard test specimens.

NDT and NDE of materials help to overcome this drawback because observations and study of failure can be performed not only on the actual geometry of parts, but also "in situ", and, in some instances, during normal operation of the equipment.

Because CDM is a versatile, fast, and inexpensive technique in the category of NDT and NDE of parts and components, this method offers ample educational possibilities to study, understand, predict and prevent failure, i.e.: the key components of safety and reliability of engineering equipment.

The applicability of CDM is extensive ranging from the test of simple pipes that have been subjected to high pressures, to sophisticated tests of reactor vessels in nuclear power plants, or the manufacturing processes of carbon-carbon based materials used in spacecraft manufacturing. Essentially, any surface that can be exposed to the CDM penetrant can be tested, and surface anomalies can be detected by the indicator material relatively fast. Furthermore, the procedure is highly safe for instructors, students, technicians and parts being tested.

From the educational point of view, CDM allows the instructor to choose academic coverage ranging from high level mathematical interpretation of phenomena to simple lab demonstration procedures to detect and show surface defects.

\section{Conclusion.}

Non Destructive Testing (NDT) of materials plays a significant role in design, manufacturing and maintenance of engineering parts, assemblies and systems. There are innumerable examples in engineering applications where NDT has become crucial for assessing and evaluating the reliability, integrity and safety of equipment that are built to satisfy human needs. 
The acquaintance of engineering students with basic principles and techniques of NDT of materials can enhance their educational experience considerably, and bring a more thorough coverage of the "materials testing" curriculum in engineering training. This is particularly true if the implementation of hands on instruction of NDT can be achieved with a modest financial investment as it is the case when using the Capillary Diffusion Method (CDM) for this purpose.

CDM for material testing is a versatile technique developed in the former Soviet Union and relatively unknown in the United States. Nevertheless, CDM has been used in the field, and continue to be used in the Russian Federation for NDT of materials in a wide variety of applications and engineering equipment such as, boilers, reactors, turbines, spacecraft, heat exchangers, etc.

CDM is an NDT technique that utilizes an inexpensive and effective liquid penetrant and indicator material, both readily available in the U.S. Procedures and materials are proprietary and patented but they are available for a modest fee ${ }^{4}$.

The technique is totally safe and portable, and does not require specialized equipment or large laboratory space. Furthermore, CDM's capability to detect surface defects surpasses the capability of similar conventional PT techniques used in the U.S. Not only that CDM is a versatile and simple NDT testing technique, but also, it offers ample educational opportunity to study a gamut of physical phenomena and several mathematical principles of engineering, as demonstrated briefly by the underlying theoretical discussion presented in this paper.

Thus, CDM is an attractive, simple and inexpensive educational tool that can bring substantial benefits to engineering curricula, and provide a more comprehensive instruction of engineering students in the areas of materials testing, as well as, safety and reliability in design, testing and monitoring of engineering equipment. The educational applicability of CDM is ample, and can be extended easily to several fields of engineering such as, Mechanical engineering, Chemical engineering, Civil engineering, Aeronautical and Aerospace engineering, Power Plant engineering and Nuclear engineering.

\section{Bibliography.}

[1] ASTM. "Nondestructive Testing Standards. A Review" American Society for Testing and Materials Technical Publication 624.

[2] Akselrud G.A., Altshuler M.A. 1983 “Введение в капиллярно-химическую технологию” (Introduction to the capillary-chemical technology). Moscow. Russsia.

[3] Beriozkina, N., Eremin, G., Larichev, M., Leipunsky I., Maklashevsky, V. 1996. "Capillary-diffusion and gasadsorption methods for non-destructive testing of materials". Izvestija RAN, Energetika. N6, p.98-112. Moscow, Russia.

[4] Beriozkina, N., Leipunsky,I., Maklashevsky, V. “Composition for use in methods for non-destructive testing of materials and wares”. United States Patent \#5,795,712.

[5] Federal Aviation Administration (FAA). U.S. Department of Transportation. 2002. "Study of the Factors Affecting the Sensitivity of Liquid Penetrant Inspections”. Report \# DOT/FAA/AR-01/95 .NTIS. Springfield, VA.

[6] Hellier, C. 2001. "Handbook of Nondestructive Evaluation". McGraw Hill. New York, NY. 
[7] Hindhele, U. 1983. "Machine Design Fundamentals, A practical Approach". Regents/Prentice Hall, Englewoods Cliffs, NJ.

[8] A. V. Kariakin, A. S. Borovikov. M., 1972 Люминесиентная и иветная дефектоскопия, М., "Машиностроение", (Luminescence and dye penetrant flaw detection). Moscow, Russia.

[9] H. Kuhling. Справочник по физике. М., "Мир", 1985 г. Handbook on physics, Moscow, Russia.

[10] Lopez, G.; Berezkina, N.; Leipunsky, I.;"Gas Adsorption Indicator Method: An innovative experimental approach for NDT Laboratory Instruction of Engineering Students”. 2004. ASEE Proceeding. Salt Lake City, UT.

[11] Marotta Control Inc. An Aerospace Company. Corporate Office. Montville, New Jersey 07045-0427. www.marotta.com

[12] McCracken, B. 1997. "Fluorescent Penetrant Method (FPM) Master". Pratt \& Whitney. U.S.A.

[13] Mix, P.; 2005 "Introduction to Nondestructive Testing; A training guide" $2^{\text {nd }}$ Ed. Wiley-Interscience. John Wiley \& Sons. Inc. Hoboken, NJ.

[14] Prokhorenko P.; Migun, N.; Введение в теорию капиллярного контроля, Минск, "Наука и техника", 1988 г. (Introduction to the theory of liquid-penetrant testing) Minsk. Belarus.

[15] Raj, B; Jayakumar, T; Thavasimuthu, M, 2002. "Practical Non-destructive Testing” ASM International. Narosa Publishing House, New Delhi.

[16] Shull, P (Editor). 2002. "Nondestructive Evaluation, Theory, Techniques and Applications". Marcel Dekker, Inc. New York, NY.

[17] Standards ASTM . 2003. "E165-02 Standard Test Method for Liquid Penetrant Examination". ASTM International. Philadelphia, PA

[18] Silberberg, M. 2003. "Chemistry: the molecular nature of matter and change". $3^{\text {rd }}$ Ed. McGraw Hill. New York, NY.

[19] J. Timmermans. The Physico-chemical Constants of Binary Systems in Concentrated Solutions. V.4, N-Y, 1960.

[20] Vasquez, I. 2003. "Fluorescent Penetrant Inspection System Performance Test Using Known Defect Standards". ASNT. U.S.A. 